\title{
Enhanced Utilization of Exogenous Glucose Improves Cardiac Function in Hypoxic Rabbit Ventricle without Increasing Total Glycolytic Flux
}

Eva M. Runnman, Scott T. Lamp, and James N. Weiss

Department of Medicine and the UCLA Cardiovascular Research Laboratory, UCLA School of Medicine, Los Angeles, California 90024

\begin{abstract}
The effects of elevated glucose on cardiac function during hypoxia were investigated in isolated arterially perfused rabbit interventricular septa. Rest tension, developed tension, intracellular potential, ${ }^{42} \mathrm{~K}^{+}$efflux, lactate production, exogenous glucose utilization, and tissue high-energy phosphate levels were measured during a 50 -min period of hypoxia with 4,5 , or $50 \mathrm{mM}$ glucose present (isosmotically balanced with sucrose) and during reoxygenation for $60 \mathrm{~min}$ with perfusate containing $5 \mathrm{mM}$ glucose $/ 45 \mathrm{mM}$ sucrose. At physiologic (4 or $5 \mathrm{mM}$ ) and supraphysiologic glucose $(50 \mathrm{mM})$, lactate production and high-energy phosphate levels during hypoxia were equally well maintained, yet cardiac dysfunction was markedly attenuated by $50 \mathrm{mM}$ glucose. Despite identical rates of total glycolytic flux, exogenous glucose utilization was enhanced by $50 \mathrm{mM}$ glucose so that tissue glycogen levels remained normal during hypoxia, whereas glycogen became depleted with 4 or $5 \mathrm{mM}$ glucose present during hypoxia. Most of the beneficial effects of $50 \mathrm{mM}$ glucose occurred during the first $25 \mathrm{~min}$ of hypoxia. Prior glycogen depletion had no deleterious effects during hypoxia with $50 \mathrm{mM}$ glucose present, but exacerbated cardiac dysfunction during hypoxia with $5 \mathrm{mM}$ glucose present. These findings indicate that enhanced utilization of exogenous glucose improved cardiac function during hypoxia without increasing total glycolytic flux or tissue high-energy phosphate levels, suggesting a novel cardioprotective mechanism. ( $J$. Clin. Invest. 1990. 86:1222-1233.) Key words: cardiac metabolism • glucose - glycolysis - hypoxia • insulin - myocardial ischemia
\end{abstract}

\section{Introduction}

Beneficial effects of glucose on impaired cardiac function were recognized as early as 1911 , when Goulston (2) reported that ingestion of cane sugar improved symptoms of heart failure in seven patients. However, it was not until the studies of SodiPallares and co-workers in the 1960 s $(3,4)$ that the concept of using glucose in combination with insulin and potassium $(\mathrm{GIK})^{1}$ to improve cardiac function and limit myocardial in-

Portions of this work were previously presented in abstract form (1988. Circulation. 78[Suppl. II]:II-261[1]).

Address reprint requests to Dr. Weiss, Division of Cardiology, 47-123 CHS, UCLA School of Medicine, Los Angeles, CA 90024.

Received for publication 1 December 1989 and in revised form 17 May 1990

1. Abbreviation used in this paper: GIK, glucose in combination with insulin and potassium.

J. Clin. Invest.

(c) The American Society for Clinical Investigation, Inc. $0021-9738 / 90 / 10 / 1222 / 12 \$ 2.00$

Volume 86, October 1990, 1222-1233 jury in the setting of ischemic heart disease gained widespread interest. Although most experimental studies demonstrated that glucose or GIK improved cardiac function and reduced injury during myocardial ischemia (5-12) or hypoxia (13-18), clinical studies have yielded conflicting results $(4,19-26)$. Some of the discrepancies may be related to the severity of ischemia, since in experimental studies the benefit of GIK during low-flow moderate ischemia was lost during severe ischemia (12), probably owing to more complete inhibition of anaerobic glycolysis and poorer delivery of substrate to the ischemic area. Both glucose alone and insulin alone have been shown to have beneficial effects $(13,14,16,26,27)$. The mechanism underlying the beneficial effects of these agents is not fully understood. Although facilitation of anaerobic glycolysis is the most obvious possibility, and is consistent with the observation that GIK increases glucose uptake during ischemia $(5,7,9,12)$, some investigators $(7,9)$ have argued that the increase in total glycolytic flux is likely to be too modest to account for the improvement in cardiac function. These considerations have led to the hypothesis that the effects of GIK may be mediated by other factors besides increased high-energy phosphate production by enhanced anaerobic glycolysis. For example, GIK has consistently been found to lower circulating levels of free fatty acids, which are known to be deleterious in the setting of myocardial ischemia, and this action has been proposed as an alternate explanation for the beneficial effects of GIK $(7,9,10)$. Other potentially significant factors include preservation of cardiac glycogen stores (28-31), membrane-stabilizing effect of insulin $(7,27)$, increased osmotic pressure (5), and free radical scavenging effects of glucose (18).

The purpose of the present study was to investigate in greater detail the metabolic effects of elevated glucose and insulin during hypoxia in order to determine whether direct metabolic effects of elevated glucose on anaerobic glycolysis underlie its well-documented beneficial effects on electromechanical function. We chose to study hypoxia for two major reasons: (a) more accurate measurements of glycolytic flux are possible than during ischemia and $(b)$ the beneficial effects of glucose on cardiac function during hypoxia have been unequivocally established (13-17). Elevated potassium was not studied to avoid its complicating effects on membrane potential. The major finding is that cardiac dysfunction during hypoxia and after reoxygenation is closely related to exogenous glucose utilization, but not total glycolytic flux (exogenous glucose utilization plus glycogenolysis). During hypoxia net glycogenolysis appears to have deleterious consequences despite the fact that high-energy phosphate levels and total glycolytic flux are maintained. Possible mechanisms for this novel observation are discussed.

\section{Methods}

Preparation and experimental setup. The experimental preparation was the arterially perfused rabbit interventricular septum. New Zea- 
land White rabbits ( $2-3 \mathrm{~kg}$ ) were heparinized and given an overdose of phenobarbital before thoracotomy. The heart was removed and the septal artery was cannulated. The well-perfused portion of the intraventricular septum was then isolated and mounted in a constant temperature $\left(37^{\circ} \mathrm{C}\right)$ nitrogen-filled chamber as described previously (32). A suture placed at the apex of the septum was tied to a tension transducer to record tension. Rest tension was set at $4 \mathrm{~g}$ for all preparations. All septa were stimulated at 75 beats/min through a bipolar platinum electrode embedded in a corner of the preparation. A perfusion pump maintained constant flow of $37^{\circ} \mathrm{C}$ perfusate through the septal artery at $1.75 \mathrm{ml} / \mathrm{min}$. Venous effluent was collected at 5 -min intervals during the experiment for metabolic assays through a polyethylene tube (PE-90) anchored at the base of the septum. Intracellular potential was monitored with floating glass microelectrodes filled with $3 \mathrm{M} \mathrm{KCl}$ as described previously (33).

Standard perfusate was a modified Tyrode's solution consisting of $110 \mathrm{mM} \mathrm{NaCl}, 4 \mathrm{mM} \mathrm{KCl}, 1.5 \mathrm{mM} \mathrm{CaCl}, 25 \mathrm{mM} \mathrm{NaHCO}_{3}, 0.44$ $\mathrm{mM} \mathrm{NaH} \mathrm{PO}_{4}, 10 \mathrm{U} /$ liter insulin, and various concentrations of glucose. All perfusates were osmotically balanced with sucrose, so that glucose + sucrose concentration equaled $50 \mathrm{mM}$. pH was maintained at 7.3-7.4 by gassing with $5 \% \mathrm{CO}_{2}$ and $95 \% \mathrm{O}_{2}$. To create hypoxia perfusate was equilibrated with $5 \% \mathrm{CO}_{2}$ and $95 \% \mathrm{~N}_{2}$.

Experimental protocol. All preparations were first equilibrated for 1-2 $\mathrm{h}$ in standard oxygenated Tyrode's perfusate containing $5 \mathrm{mM}$ glucose $/ 45 \mathrm{mM}$ sucrose, and then subjected to a 50 -min period of hypoxia, in the presence of isosmotic (sucrose-balanced) Tyrode's solution containing $0,2.5,4,5$, or $50 \mathrm{mM}$ glucose. Preparations were either immediately freeze-clamped at the end of the hypoxic period, or were reoxygenated for $1 \mathrm{~h}$ with $5 \mathrm{mM}$ glucose $/ 45 \mathrm{mM}$ sucrose Tyrode's solution and then freeze clamped. Developed and rest tension, intracellular potential, and effluent lactate content were monitored in all experiments, and in some experiments ${ }^{42} \mathrm{~K}^{+}$efflux or $\left[{ }^{3} \mathrm{H}\right]$ glucose uptake were also monitored. Some preparations were glycogen-depleted before hypoxia by exposing the preparation to oxygenated glucose-free Tyrode's solution for $\sim 1 \mathrm{~h}$ until developed tension declined to a steady level $\sim 50 \%$ of control. In other experiments insulin was removed from all perfusates.

Metabolic assays. Venous effluent samples were placed on ice immediately. Lactate content was determined by standard spectrophotometric techniques $(34,35)$ using a spectrophotometer (model DU8, Beckman Instruments, Inc., Palo Alto, CA). For determination of tissue metabolites, preparations were quickly smash-frozen between copper blocks precooled in liquid nitrogen. Approximately $200 \mathrm{mg}$ samples of the tissue were pulverized and extracted in $3 \mathrm{M}$ perchloric acid. Tissue content of ATP, ADP, AMP, creatine phosphate, creatine, and cyclic AMP were determined by high pressure liquid chromatography as previously described (35-37). Tissue glycogen levels were determined by extracting the tissue with $7 \mathrm{M} \mathrm{NaOH}$ and precipitating the glycogen with ethanol (38). The precipitated glycogen was then suspended in water and digested by amyloglucosidase to glucosyl units, which were assayed spectrophotometrically.

Radioisotopic techniques. To monitor glucose utilization 1.0-2.0 $\mu \mathrm{Ci} / \mathrm{ml}$ of $\left[2-{ }^{3} \mathrm{H}\right]$ glucose (New England Nuclear, Boston, MA) was added to perfusate $(39,40)$. Aliquotes of the venous effluent $(0.2 \mathrm{ml})$ were placed on chromatography columns (bed size $0.8 \times 4 \mathrm{~cm}$, BioRad Laboratories, Richmond, CA), filled to $2 \mathrm{~cm}$ height with resin. To improve glucose binding, the column packing resin (Bio-Rad Laboratories $\mathrm{AG} 1-\mathrm{X} 8 \mathrm{Cl}^{-}$) was ion-exchanged before use by continuously mixing original resin with $7 \mathrm{M} \mathrm{NaOH}$ over $96 \mathrm{~h}$. The initial eluent from the column (first $20 \mathrm{~min}$ ) was then assayed for tritiated water content, using $15 \mathrm{ml}$ of scintillation fluid (Scintiverse, Fisher Scientific Co., Pittsburgh, PA) in a beta counter. The tritiated water production measured is directly related to exogenous glucose utilized. Tritiated water counts were corrected for contamination from $\left[{ }^{3} \mathrm{H}\right]$ glucose escaping the column by running a $0.2-\mathrm{ml}$ sample of perfusate containing $\left[{ }^{3} \mathrm{H}\right]$ glucose through the column and counting the 20 -min eluent fraction. The contamination was $<0.2 \%$ of total eluent counts in the venous effluent. Counts were also adjusted for percent yield of tritiated water from the column, which consistently was $>90 \%$ when a known amount of tritiated water standard was passed through the column. To determine if $\left[{ }^{3} \mathrm{H}\right]$ glucose was incorporated into myocardial glycogen to a significant extent during the time course of the experiment, aliquotes of glycogen isolated from tissue samples from each $\left[{ }^{3} \mathrm{H}\right]$ glucose experiment (as described above) were suspended in water and counted using the same technique. No $\left[{ }^{3} \mathrm{H}\right]$ glucose could be detected in the glycogen suspensions, suggesting that glycogen synthesis in this preparation may occur predominantly by the gluconeogenic pathway rather than direct incorporation from glucose-6-phosphate (41).

To measure unidirectional ${ }^{42} \mathrm{~K}^{+}$efflux, septa were loaded with perfusate containing ${ }^{42} \mathrm{~K}^{+}(1.75 \mu \mathrm{Ci} / \mathrm{ml})$ for $45 \mathrm{~min}$ and then washed out for $20 \mathrm{~min}$ to establish the control rate of ${ }^{42} \mathrm{~K}^{+}$efflux before exposure to hypoxic perfusate. Venous effluent was collected for $30 \mathrm{~s}$ of each $1-\mathrm{min}$ interval and analyzed for radioactivity (counts per minute) in a gamma counter. After correction of effluent counts per minute for background and decay, unidirectional ${ }^{42} \mathrm{~K}^{+}$efflux rate (in micromoles per gram per minute) was calculated as described previously (42).

Data analysis. All results are expressed as mean $\pm \mathrm{SE}$ in both text and figures. Statistical significance was evaluated with unpaired Student's $t$ tests using the Bonferroni correction for comparisons of multiple groups. $P \leq 0.05$ was taken to indicate a statistically significant difference.

\section{Results}

Effect of glucose on cardiac function during hypoxia. Fig. 1 compares tension, action potential duration, and lactate production in three typical preparations exposed to either 0,5 , or $50 \mathrm{mM}$ glucose during a $50-\mathrm{min}$ period of hypoxia followed by reoxygenation for $1 \mathrm{~h}$ with Tyrode's solution containing $5 \mathrm{mM}$ glucose. With $5 \mathrm{mM}$ glucose present during hypoxia (middle tracing), a large contracture and decrease in developed tension occurred with incomplete recovery upon reoxygenation. Action potential duration also shortened significantly. Lactate production was maintained throughout hypoxia. In contrast, the functional abnormalities when $50 \mathrm{mM}$ glucose was present in the hypoxic perfusate were much less severe (lower tracing). There was no contracture during hypoxia, less depression of developed tension, and better recovery of mechanical function recovery upon reoxygenation. Action potential duration was minimally shortened and lactate production was well maintained. It is noteworthy that despite the marked differences in electromechanical function with $5 \mathrm{mM}$ and $50 \mathrm{mM}$ glucose present during hypoxia, lactate production, the marker of anaerobic ATP production, was similar. For comparison, an example of hypoxia without glucose is also shown (upper tracing). Lactate production (lower graph) initially increased but then fell, accompanied by much more severe electromechanical dysfunction with no recovery following reoxygenation.

Fig. 2 summarizes changes in cardiac function during hypoxia with 50,5 , and $4 \mathrm{mM}$ glucose present. With $50 \mathrm{mM}$ glucose present during hypoxia, there was minimal contracture during hypoxia as rest tension increased slightly from the control level of 4.0 to $4.45 \pm 0.04 \mathrm{~g}$. At physiologic glucose concentrations, however, the increase in rest tension was significantly greater, reaching $6.95 \pm 0.45$ and $7.86 \pm 0.58 \mathrm{~g}$ for 5 and $4 \mathrm{mM}$ glucose, respectively. At $50 \mathrm{~min}$ of hypoxia, the differences between 50 and 5 or $4 \mathrm{mM}$ glucose were statistically significant $(P<0.01)$. Recovery of rest tension after 60 min of reoxygenation with $5 \mathrm{mM}$ glucose $/ 45 \mathrm{mM}$ sucrose perfusate was complete when $50 \mathrm{mM}$ glucose was present during hypoxia $(4.0 \pm 0.3 \mathrm{~g})$, but significant contracture persisted with either 5 or $4 \mathrm{mM}$ glucose $(5.76 \pm 0.77 \mathrm{~g}$; $P$ not significant $)$. 

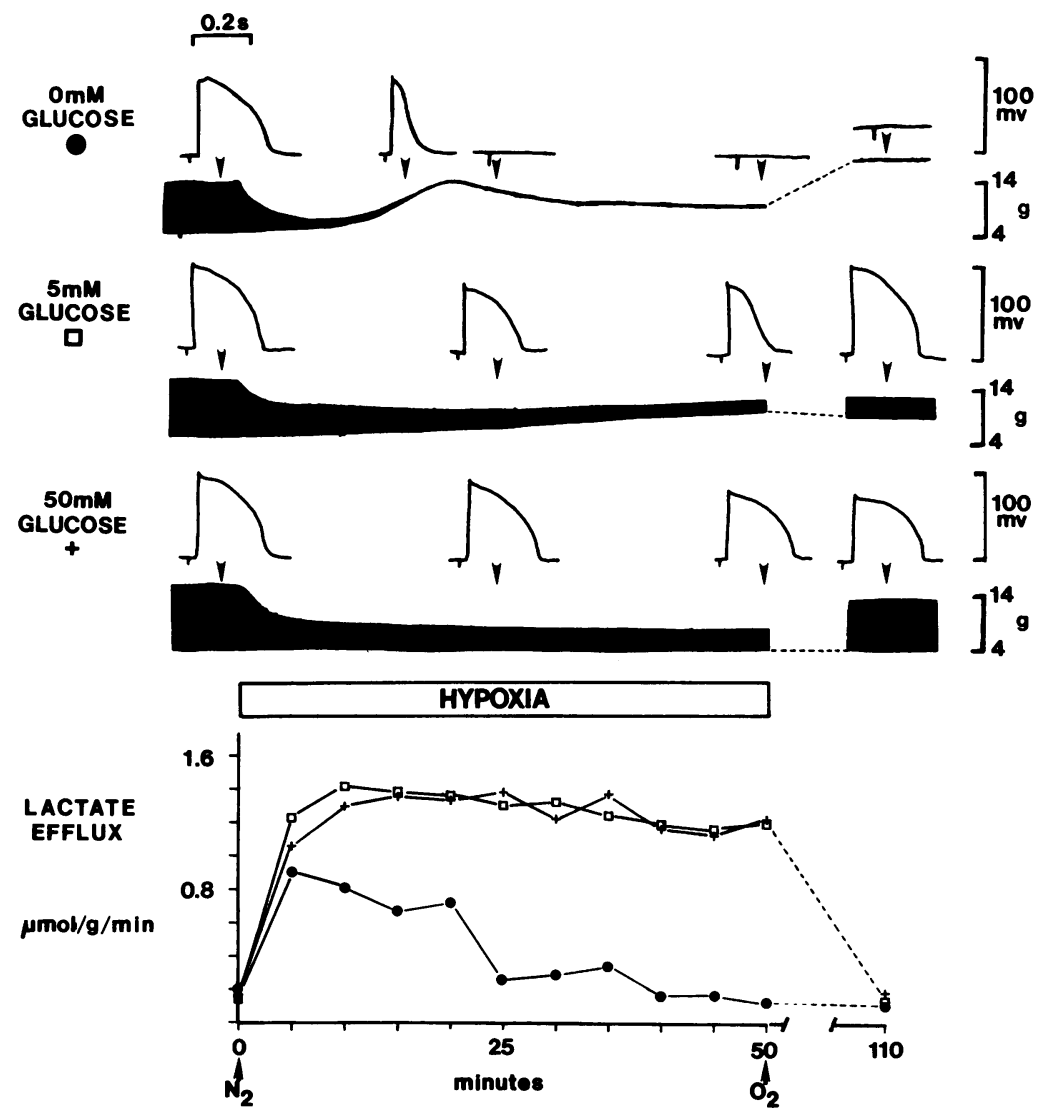

Figure 1. Effects of glucose on tension, the action potential, and effluent lactate content during hypoxia and reoxygenation. The upper tracings show tension development and action potentials (recorded at the arrows) during a 50-min period of hypoxia and after $60 \mathrm{~min}$ of reoxygenation (following dashed lines) in three representative preparations with either 0,5 , or $50 \mathrm{mM}$ glucose present during the hypoxic period. All three preparations were reoxygenated with perfusate containing 5 $\mathrm{mM}$ glucose. Lower graph shows the rate of net lactate loss in the venous effluent ( $0 \mathrm{mM}$ glucose, $\bullet ; 5 \mathrm{mM}$ glucose, $\square ; 50 \mathrm{mM}$ glucose, +). Action potentials were traced from the original oscilloscope photographs.

Developed tension (Fig. 2, upper right panel) fell less with $50 \mathrm{mM}$ glucose present, decreasing to $33 \pm 1 \%$ of control after 50 min of hypoxia. With 5 or $4 \mathrm{mM}$ glucose present during hypoxia, developed tension was more severely depressed, fall- ing to $19 \pm 2 \%$ and $22 \pm 2 \%$ of control, respectively, after $50 \mathrm{~min}$ of hypoxia. These differences were statistically significant $(P$ $<0.01$ for hypoxia with 5 vs. $50 \mathrm{mM}$ glucose; $P<0.05$ for hypoxia with 4 vs. $50 \mathrm{mM}$ glucose). Recovery of developed
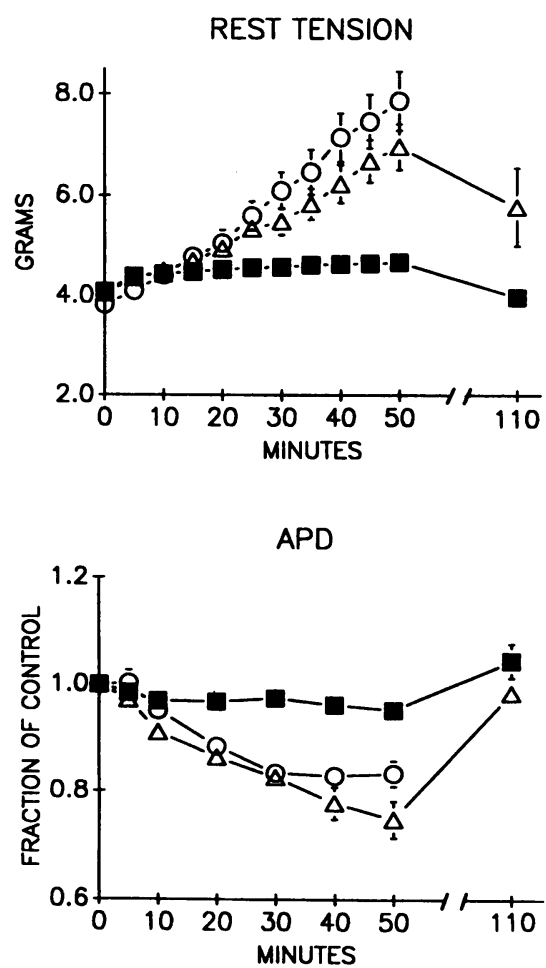

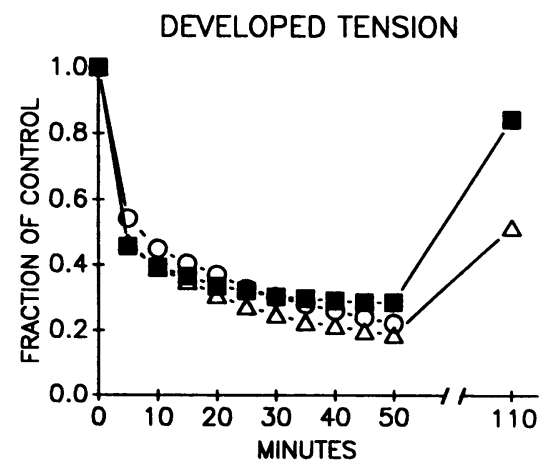

[GLUCOSE] $n$

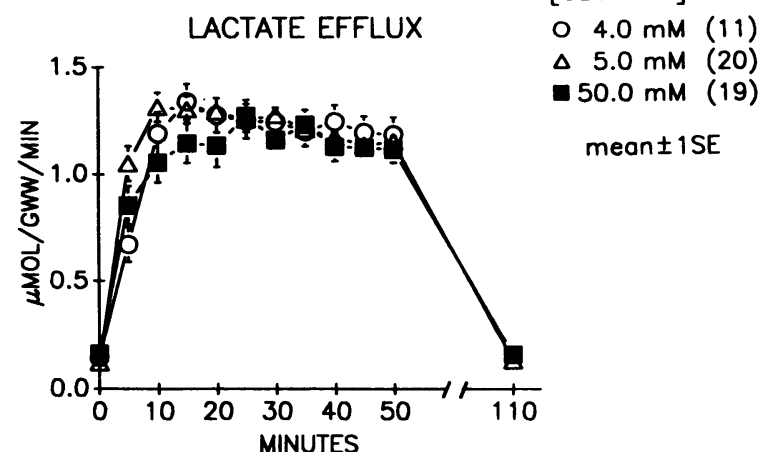

Figure 2. Effects of glucose on cardiac function during hypoxia and reoxygenation. Changes in rest tension, developed tension, action potential duration $(A P D)$, and effluent lactate efflux are summarized during hypoxia $(0-50 \mathrm{~min})$ in the presence of glucose concentrations of 4 $\mathrm{mM}(\mathrm{O}, n=11), 5 \mathrm{mM}(\Delta, n$ $=20)$, or $50 \mathrm{mM}(\mathrm{m}, n=19)$. Some preparations exposed 5 $\mathrm{mM}(n=13)$ and $50 \mathrm{mM}(n$ $=10$ ) glucose during hypoxia were subsequently reoxygenated for $60 \mathrm{~min}(50-110$ $\mathrm{min}$ ) with perfusate containing $5 \mathrm{mM}$ glucose to assess recovery of function. Values are the mean $\pm 1 \mathrm{SE}$. SE bars are shown only if larger than the symbols. GWW, grams wet weight. 


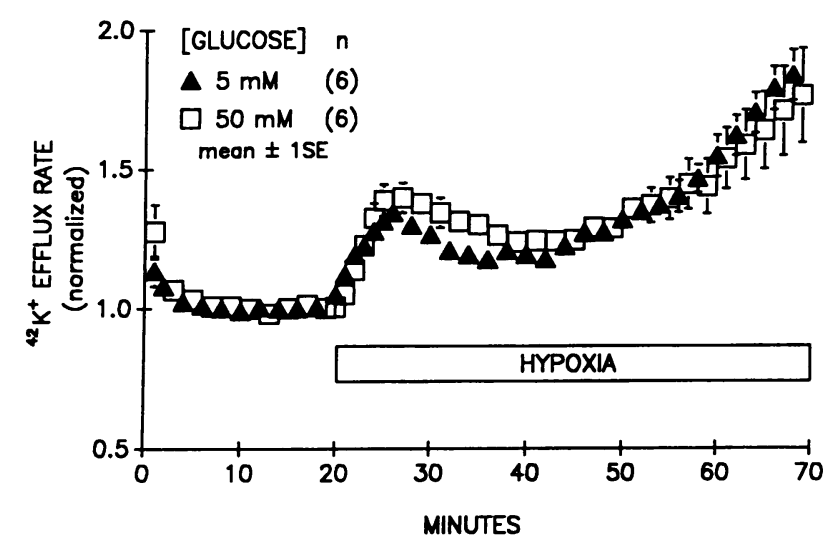

Figure 3. Effects of 5 vs. $50 \mathrm{mM}$ glucose on ${ }^{42} \mathrm{~K}^{+}$efflux rate during hypoxia. Same protocol as in Fig. 2 , with ${ }^{42} \mathrm{~K}^{+}$washout starting at time zero. $\mathrm{K}^{+}$efflux rate is normalized to the control rate $(0-20$ $\mathrm{min}$ ), which averaged $1.4 \pm 0.2$ and $1.1 \pm 0.2 \mu \mathrm{mol} / \mathrm{g}$ per min, respectively, in six hearts exposed to either $5 \mathrm{mM}$ glucose ( $\triangle$ ) or $50 \mathrm{mM}$ glucose ( $\square$ ) during hypoxia. Values represent the mean $\pm 1 \mathrm{SE}$. SE bars are shown only if larger than the symbols.

tension after $1 \mathrm{~h}$ of reoxygenation was greater after hypoxia with $50 \mathrm{mM}$ glucose present (to $84 \pm 3 \%$ of control) than with 5 $\mathrm{mM}$ glucose (52 $\pm 4 \%$ of control, $P<0.005$ ).

There was mild shortening of the action potential duration to $95 \pm 2 \%$ of control after $50 \mathrm{~min}$ with $50 \mathrm{mM}$ glucose present during hypoxia (Fig. 2, lower left panel). With 5 or $4 \mathrm{mM}$ glucose action potential shortening during hypoxia was more marked, declining to $75 \pm 3 \%$ and $83 \pm 2 \%$ of control respectively ( $P<0.01$ compared to $50 \mathrm{mM}$ glucose). Recovery of action potential duration after $60 \mathrm{~min}$ of reoxygenation was similar in all groups.

Despite the significant differences in electromechanical function during and after hypoxia with 50 and 5 or $4 \mathrm{mM}$ glucose present, there were no significant differences in effluent lactate content during hypoxia between the groups (Fig. 2 , lower right panel). A steady-state level of $\sim 1.20 \pm 0.045$ $\mu \mathrm{mol} / \mathrm{g}$ per min was reached within $10 \mathrm{~min}$ and maintained throughout the hypoxic period. To test the threshold at which lactate production was maintained during hypoxia, we also studied a group of seven hearts with $2.5 \mathrm{mM}$ glucose in the hypoxic perfusate. At this glucose concentration lactate production was not maintained, falling to $0.58 \pm 0.15 \mu \mathrm{mol} / \mathrm{g}$ per min after $50 \mathrm{~min}$ of hypoxia $(P<0.01$ compared to 4,5 , or 50
$\mathrm{mM}$ glucose). Consistent with the lower lactate production, the increase in rest tension (to $14.03 \pm 1.36 \mathrm{~g}$ ) and fall in developed tension (to $7 \pm 0 \%$ of control) were greater after $50 \mathrm{~min}$ of hypoxia than with 4,5 , or $50 \mathrm{mM}$ glucose present $(P<0.01)$. Shortening of action potential duration was similar to that with 4 or $5 \mathrm{mM}$ glucose present (to $73 \pm 6 \%$ of control; $P$ not significant).

Fig. 3 compares the effects of 50 and $5 \mathrm{mM}$ glucose on ${ }^{42} \mathrm{~K}^{+}$ efflux during hypoxia. The increase in ${ }^{42} \mathrm{~K}^{+}$efflux during 50 min of hypoxia was similar in both groups.

Levels of high energy phosphates and cyclic AMP during hypoxia. To determine whether the beneficial effects of 50 $\mathrm{mM}$ glucose were associated with better preservation of cellular high-energy phosphate stores, levels of adenine nucleotides and creatine phosphate were measured at the end of hypoxic episode in the presence of 50,5 , and 4 glucose. Fig. 4 shows that there were no significant differences in high-energy phosphate levels between the different groups. These findings are consistent with the observation that total lactate production, the primary marker of high energy phosphate production during hypoxia, was the same in all three groups. Tissue levels of cyclic AMP were also measured and were similar in all the groups.

Exogenous glucose utilization during hypoxia. In light of large differences in electromechanical function during hypoxia and reoxygenation with 50 and 5 or $4 \mathrm{mM}$ glucose present, the finding that total glycolytic flux and tissue high-energy phosphate levels were nearly identical indicates that enhancement of total anaerobic high-energy phosphate production could not explain the beneficial effects of high glucose during hypoxia. To further investigate the effects of glucose on anaerobic glycolysis during hypoxia we measured exogenous glucose utilization with $\left[{ }^{3} \mathrm{H}\right]$ glucose (Fig. 5). In 18 preparations, the control rate of glucose utilization under oxygenated conditions was $0.12 \pm 0.010 \mu \mathrm{mol}$ glucose $/ \mathrm{g}$ per min. The ratio of glucose utilized to lactate produced was $0.63 \pm 0.05$, indicating that a significant portion of lactate produced was being further metabolized oxidatively. During hypoxia glucose utilization increased (Fig. 5, middle panel) and with $50 \mathrm{mM}$ glucose present reached a higher steady-state level $(0.66 \pm 0.07 \mu \mathrm{mol} / \mathrm{g}$ per min $)$ than with 5 or $4 \mathrm{mM}$ glucose $(0.42 \pm 0.04$ and $0.40 \pm 0.01$ $\mu \mathrm{mol} / \mathrm{g}$ per min, respectively). Furthermore, as shown in the lower panel of Fig. 5, during hypoxia with $50 \mathrm{mM}$ glucose the ratio of glucose utilized to lactate produced averaged $0.49 \pm 0.02$, indicating that virtually all of the lactate produced
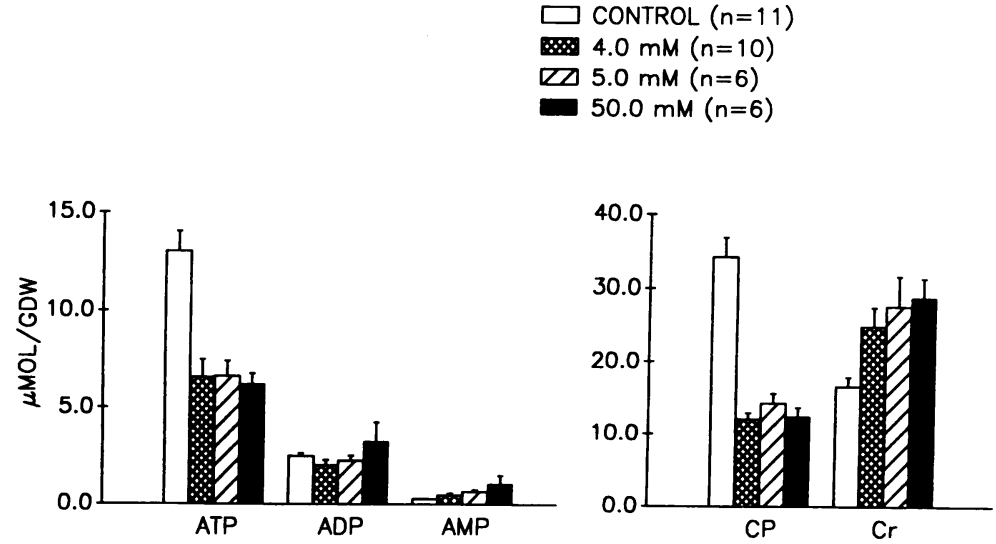

Figure 4. Tissue content of ATP, ADP, AMP, creatine phosphate $(C P)$, creatine $(C r)$, and cyclic AMP (cAMP) under control oxygenated conditions and after $50 \mathrm{~min}$ of hypoxia with either 4,5 , or $50 \mathrm{mM}$ glucose present. Values represent the mean $\pm 1 \mathrm{SE}$ for the number of hearts indicated. GDW, grams dry weight. 

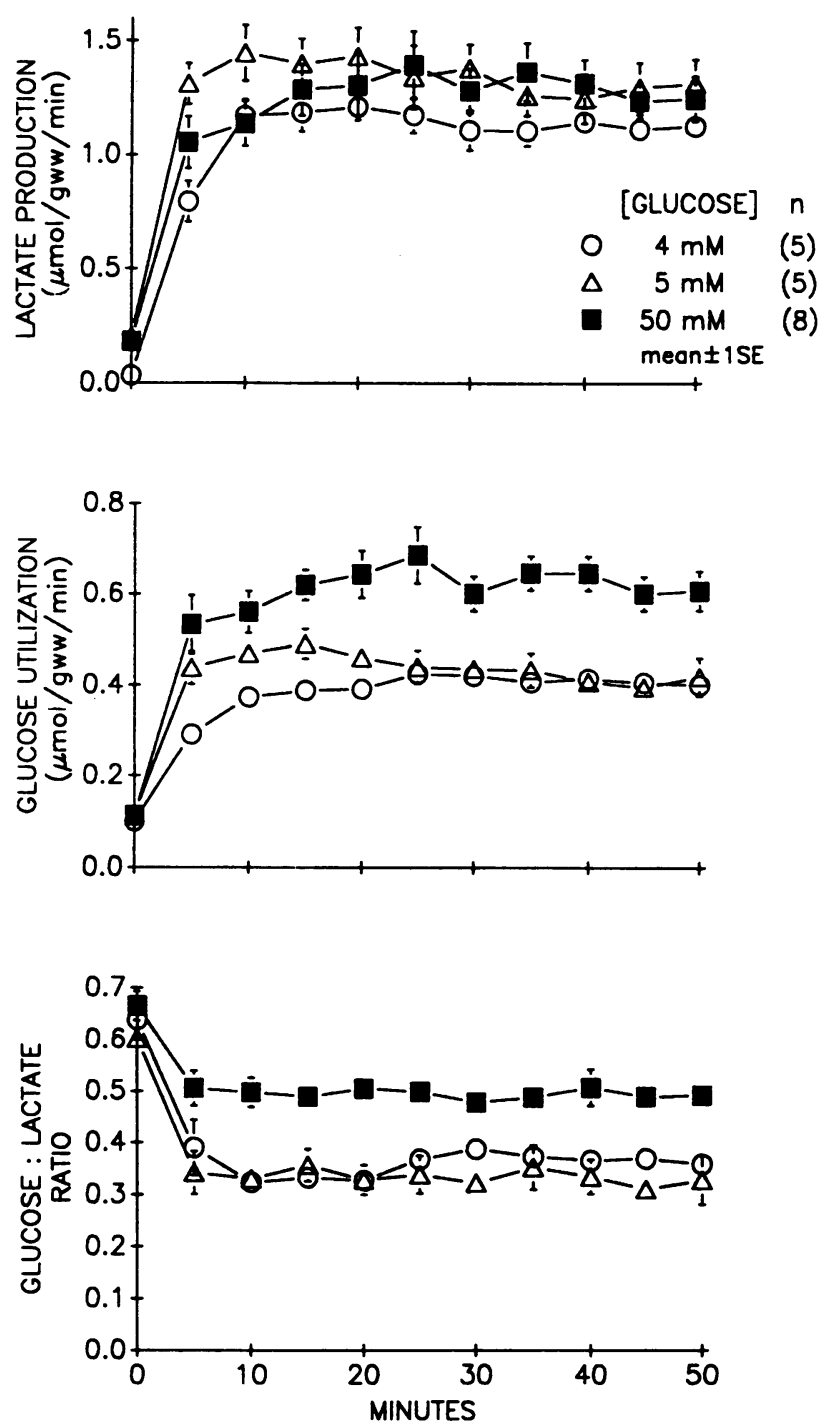

Figure 5. Effect of glucose concentration during hypoxia on lactate production (upper graph), exogenous glucose utilization (middle graph), and the ratio of glucose utilized to lactate produced (lower graph) during hypoxia (0-50 $\mathrm{min})$. The glucose concentration during hypoxia was either $4 \mathrm{mM}(0, n=5), 5 \mathrm{mM}(\Delta, n=5)$, or $50 \mathrm{mM}(n$, $n=8$ ). Values are the mean \pm 1 SE. SE bars are shown only if larger than the symbols.

could be accounted for by metabolism of exogenous glucose (since two lactate molecules are produced for each glucose molecule metabolized anaerobically). In contrast, during hypoxia with either 5 or $4 \mathrm{mM}$ glucose present, the ratio of glucose utilized to lactate produced was $0.33 \pm 0.05$ and $0.36 \pm 0.02$, respectively $(P<0.001$ for 5 vs. 50 and $P<0.05$ for 4 vs. 50 $\mathrm{mM}$ glucose). A ratio below 0.5 indicates that a nonlabeled glucose source, e.g., endogenous glycogen, was contributing to lactate production. These results suggest that in the presence of $50 \mathrm{mM}$ glucose the total lactate produced during hypoxia could be accounted for by metabolism of exogenous glucose, i.e., no net glycogenolysis occurred. In the presence of 5 and 4 $\mathrm{mM}$ glucose on the other hand, total glycolytic flux during hypoxia was similar, but net glycogenolysis made a significant contribution (about $30 \%$ ) to total lactate produced.
Tissue glycogen depletion during hypoxia. If the above results are correct, then tissue glycogen levels should remain normal during hypoxia with $50 \mathrm{mM}$ glucose present, but become depleted with 5 or $4 \mathrm{mM}$ glucose present during hypoxia. Fig. 6 shows that this was the case. In control experiments the initial glycogen content was $118 \pm 5.3 \mu \mathrm{mol} / \mathrm{g}$ dry weight after $30 \mathrm{~min}$ of equilibration in oxygenated Tyrode's solution and fell to $67.2 \pm 5.2 \mu \mathrm{mol} / \mathrm{g}$ after an additional period of continued aerobic perfusion of $2.5 \mathrm{~h}$ (equivalent to the average equilibration period + hypoxic period in the hypoxia experiments). In the hearts exposed to $50 \mathrm{mM}$ glucose during hypoxia the glycogen level at the end of the hypoxic period was unchanged $(68.5 \pm 9.1 \mu \mathrm{mol} / \mathrm{g})$. In contrast, during hypoxia with 5 or 4 $\mathrm{mM}$ glucose in the perfusate glycogen content was significantly reduced at the end of the hypoxic period, to $42.9 \pm 4.0$ and $48.2 \pm 3.5 \mu \mathrm{mol} / \mathrm{g}$ respectively $(P<0.05$ control $\mathrm{vs}$. $5 \mathrm{mM}$ glucose, $P$ not significant for control vs. $4 \mathrm{mM}$ glucose).

Effect of glycogen depletion on cardiac function during hypoxia. Since above results indicate that glycogen depletion during hypoxia was associated with more severe electromechanical dysfunction and poorer recovery upon reoxygenation, the effects of glycogen-depleting hearts before hypoxia was studied (Fig. 7). Preparations were glycogen depleted by perfusion with oxygenated glucose-free perfusate for $1 \mathrm{~h}$, which reduced developed tension by $\sim 50 \%$. With $50 \mathrm{mM}$ glucose present, glycogen-depleted preparations maintained lactate production during hypoxia and changes in rest tension, developed tension, or action potential duration shortening were almost identical to those in non-glycogen-depleted hearts. During hypoxia in the presence of $5 \mathrm{mM}$ glucose, however, glycogen-depleted preparations tended to be more impaired than non-glycogendepleted preparations. Lactate production, after an initial increase similar to the non-glycogen-depleted hearts, dropped to $0.72 \pm 0.08 \mu \mathrm{mol} / \mathrm{g}$ per min after $50 \mathrm{~min}$ of hypoxia $(P<0.001$ compared to non-glycogen-depleted hearts; Fig. 7, lower right panel). The increase in rest tension was similar in both groups (Fig. 7, upper left panel), although recovery after reoxygenation was slightly worse in glycogen-depleted hearts $(6.6 \pm 0.7 \mathrm{vs}$. $5.8 \pm 0.8 \mathrm{~g}, P$ not significant). Developed tension (Fig. 7, upper right panel) was more severely depressed in the glycogen-depleted hearts ( $11 \pm 4 \%$ vs. $19 \pm 2 \%$ of control, $P$ not significant), and also showed poorer recovery after reoxygenation (to

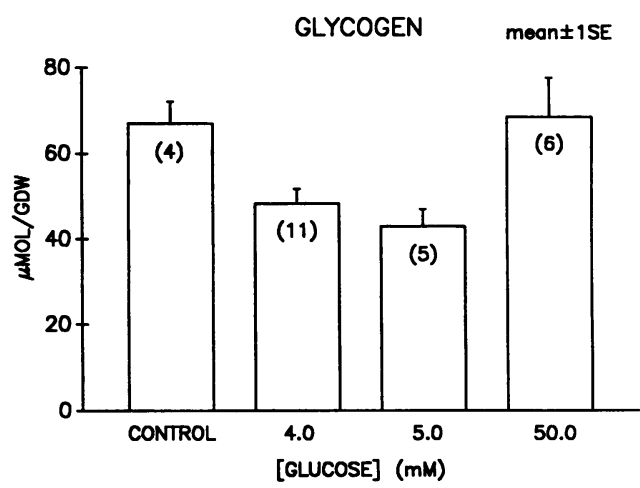

Figure 6. Effect of glucose concentration during hypoxia on tissue glycogen levels. Values are the mean \pm 1 SE for the number of preparations indicated in parentheses under control oxygenated conditions and after $50 \mathrm{~min}$ of hypoxia with 4,5 , or $50 \mathrm{mM}$ glucose present. GDW, grams dry weight. 
REST TENSION

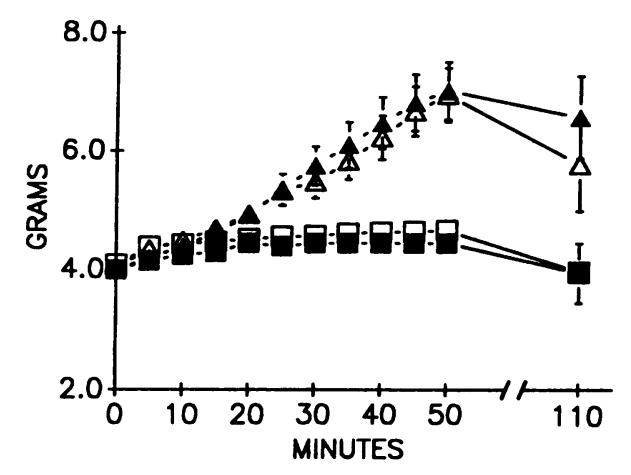

APD

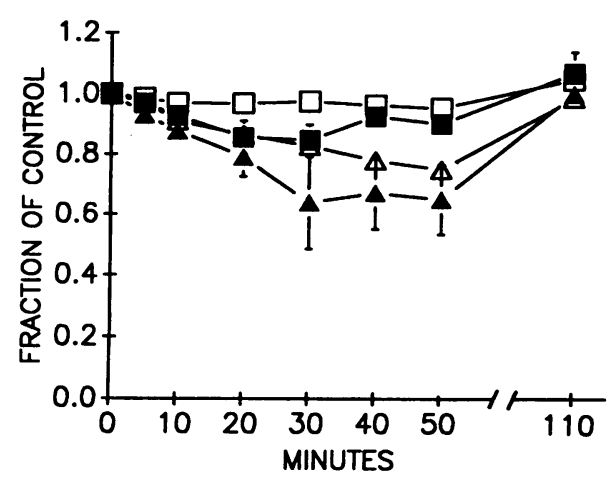

DEVELOPED TENSION

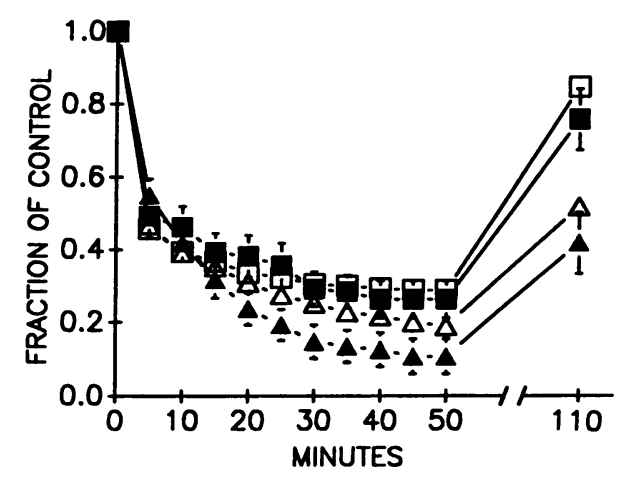

[GLUCOSE] $n$

$\triangle 5.0 \mathrm{mM}, \mathrm{C}(20)$

$\triangle 5.0 \mathrm{mM}, \mathrm{GD}(8)$

$\square 0.0 \mathrm{mM}, \mathrm{C}(19)$

- $50.0 \mathrm{mM}, \mathrm{GD}(4)$

mean $\pm 1 S E$

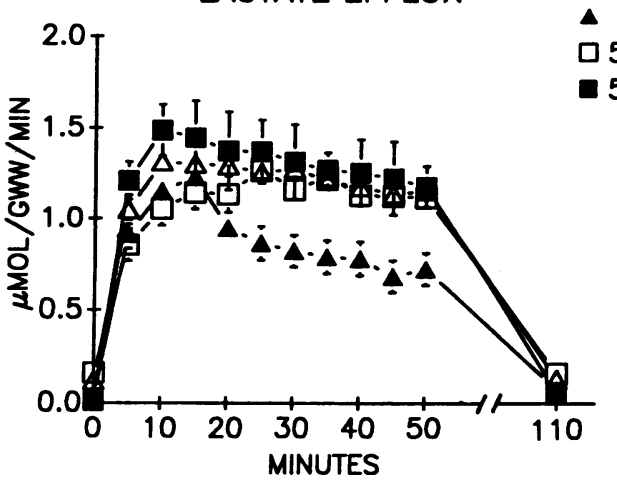

Figure 7. Effects of glucose on cardiac function during hypoxia and reoxygenation in normal ( $C$, open symbols) vs. glycogen-depleted ( $G D$, solid symbols) preparations. Changes in rest tension, developed tension, action potential duration (APD), and effluent lactate efflux are summarized during hypoxia (0-50 min) with either $5 \mathrm{mM}$ (triangles) or $50 \mathrm{mM}$ (squares) glucose present. Recovery of function is shown after $60 \mathrm{~min}$ of reoxygenation (50-110 min) with $5 \mathrm{mM}$ glucose present in all cases. Values are the mean $\pm 1 \mathrm{SE}$. SE bars are shown only if larger than the symbols. GWW, grams wet weight.

$41 \pm 8 \%$ vs. $52 \pm 4 \%$ of control). Action potential duration (Fig. 7 , lower left panel) shortened to a slightly greater extent in glycogen-depleted hearts $(65 \pm 7 \%$ vs. $69 \pm 3 \%$ of control, $P$ not significant). Although most of these differences did not achieve statistical significance, the trends suggest that glycogen stores are more important to the maintenance of cardiac function during hypoxia with 5 or $4 \mathrm{mM}$ glucose present than with 50 $\mathrm{mM}$ glucose in the perfusate.

Effect of insulin during hypoxia. The effect of insulin on cardiac function during hypoxia in the presence of $5 \mathrm{mM}$ glucose was also studied (Fig. 8). In the absence of insulin preparations were unable to maintain lactate production during hypoxia, which fell to $0.75 \pm 11 \mu \mathrm{mol} / \mathrm{g}$ per min at the end of the hypoxic period compared to $1.22 \pm 0.05 \mu \mathrm{mol} / \mathrm{g}$ per min with insulin present $(P<0.001 ;$ Fig. 8 , lower right panel $)$. The increase in rest tension during hypoxia was greater without insulin, rising to $8.0 \pm 0.6$ vs. $7.0 \pm 0.5$ with insulin present $(P$ not significant; Fig. 8, upper left panel). Recovery upon reoxygenation was also slightly worse in the absence of insulin ( $6.6 \pm 0.7$ vs. $5.8 \pm 0.8 \mathrm{~g}, P$ not significant). The fall in developed tension during hypoxia without insulin (Fig. 8, upper right panel) was significantly greater $(9 \pm 2 \%$ vs. $19 \pm 2 \%$ of control, $P$ $<0.01$ ), and recovery after reoxygenation was less complete (to $42 \pm 8 \%$ vs. $52 \pm 4 \%$ of control). Action potential duration shortening during hypoxia (Fig. 8, lower left panel) was slightly greater without insulin, $(65 \pm 6 \%$ vs. $69 \pm 3 \%$ of control, $P$ not significant).
Time course of the effects of elevated glucose during hypoxia. To determine whether elevated glucose benefited cardiac function during hypoxia in a time-dependent fashion, two groups of preparations were compared. The first group $(n=4)$ was exposed to $50 \mathrm{mM}$ glucose during the first $25 \mathrm{~min}$ of hypoxia, and to $5 \mathrm{mM}$ glucose during the second $25 \mathrm{~min}$. In the second group $(n=5)$ the order was reversed. Both groups of hearts were reoxygenated with perfusate containing $5 \mathrm{mM}$ glucose for $60 \mathrm{~min}$ to assess functional recovery. As shown in Fig. 9, lactate production was similar in both groups, but function was better preserved in the hearts exposed to $50 \mathrm{mM}$ glucose during the first $25 \mathrm{~min}$ of hypoxia. After $50 \mathrm{~min}$ of hypoxia in this group, rest tension increased less (to $4.8 \pm 0.4$ vs. $6.7 \pm 0.4 \mathrm{~g}, P<0.02$ ), developed tension was less depressed (to $14 \pm 8 \%$ vs. $5 \pm 2 \%$ of control, $P$ not significant) and action potential duration better maintained $(88 \pm 5 \%$ vs. $69 \pm 5 \%$ of control, $P=0.05$ ). Recovery of mechanical function after reoxygenation was also better. These results suggest that the beneficial effects of $50 \mathrm{mM}$ glucose on cardiac function during hypoxia are most important during the initial $25 \mathrm{~min}$.

\section{Discussion}

Significance of the present findings in relation to previously proposed mechanisms of the beneficial effects of elevated glucose. The results of this study confirm the previous observations which have established that elevated glucose has benefi- 

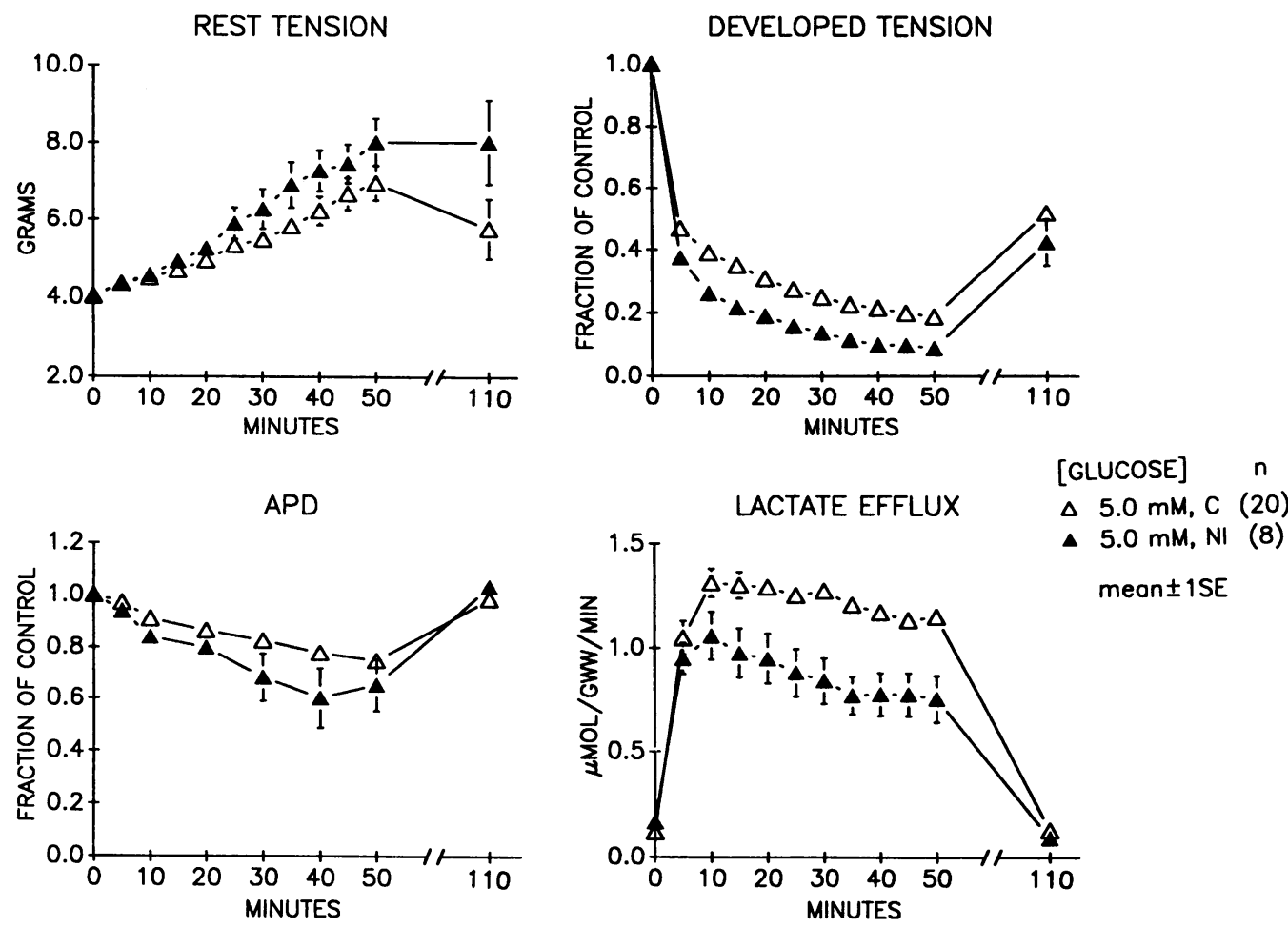

\begin{abstract}
Figure 8. Effects of glucose on cardiac function during hypoxia and reoxygenation in the presence $(C, \Delta)$ and absence $(N I, \Delta)$ of insulin. Changes in rest tension, developed tension, action potential duration (APD), and effluent lactate efflux are summarized during hypoxia (0-50 $\mathrm{min})$ and after $60 \mathrm{~min}$ of reoxygenation (50-110 $\mathrm{min}$ ) with $5 \mathrm{mM}$ glucose present. Values are the mean \pm 1 SE. SE bars are shown only if larger than the symbols. GWW, grams wet weight.
\end{abstract}

cial effects on electromechanical cardiac function during and after recovery from hypoxia. The novel finding is that the improvement in cardiac function produced by elevated glucose during hypoxia was independent of total glycolytic flux and tissue high-energy phosphate content, but closely correlated with the rate of exogenous glucose utilization during hypoxia. At both physiologic (4 and $5 \mathrm{mM}$, or 72 and $90 \mathrm{mg} \%$, respectively) and supraphysiologic ( $50 \mathrm{mM}$ or $900 \mathrm{mg} \%$ ), total glycolytic flux and tissue high-energy phosphate content were identical during hypoxia despite a marked attenuation in the severity of cardiac dysfunction at the high glucose concentration. The only metabolic difference identified between hypoxia with a physiologic or supraphysiologic glucose concentration was an increase in exogenous glucose utilization in the

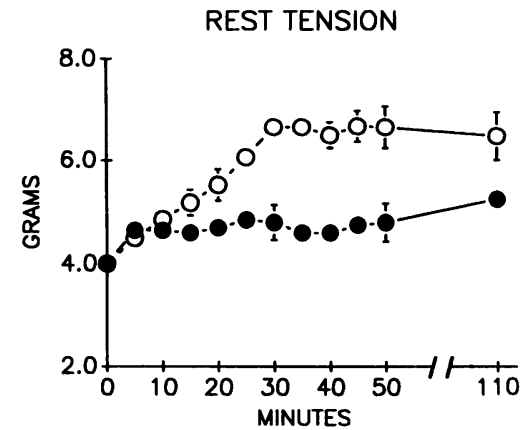

APD

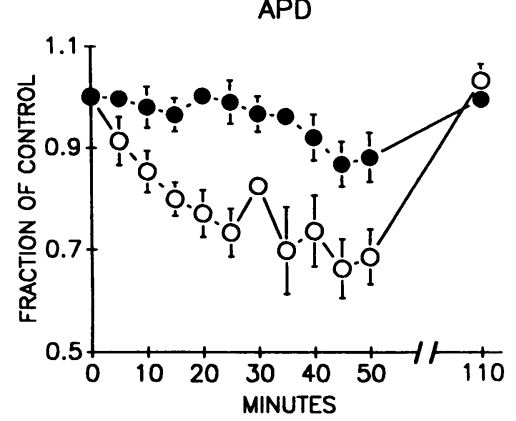

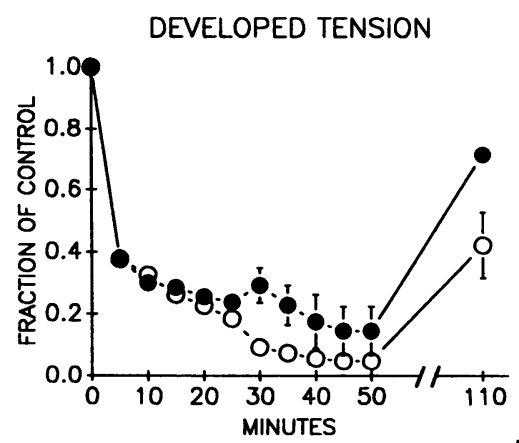

[GLUCOSE] $n$

- $5 \rightarrow 50 \mathrm{mM}(5)$

LACTATE EFFLUX

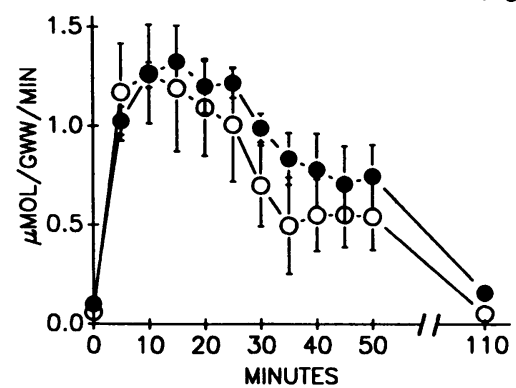

Figure 9. Time dependence of the beneficial effects of $50 \mathrm{mM}$ glucose during hypoxia. Changes in rest tension, developed tension, action potential duration $(A P D)$, and effluent lactate efflux are summarized during hypoxia (0-50 $\mathrm{min})$ and after 60 min of reoxygenation (50-110 $\mathrm{min}$ ) in two groups of hearts. One group (o) was exposed to $5 \mathrm{mM}$ glucose during the initial $25 \mathrm{~min}$ of hypoxia and to $50 \mathrm{mM}$ glucose during the final $25 \mathrm{~min}$. In the other group (•) the order was reversed. Values are the mean \pm 1 SE. SE bars are shown only if larger than the symbols. GWW, grams wet weight. 
latter case. Despite identical rates of total glycolytic flux, when $50 \mathrm{mM}$ glucose was present during hypoxia virtually all lactate production could be accounted for by exogenous glucose utilization, but only $\sim 70 \%$ when 4 or $5 \mathrm{mM}$ glucose were present, the remainder originating from glycogenolysis. Cardiac glycogen measurements confirmed these results, demonstrating that tissue glycogen levels at the end of the hypoxic period were unchanged from control with $50 \mathrm{mM}$ glucose present, but significantly depleted with the lower glucose concentrations. Thus enhanced utilization of exogenous glucose improved cardiac function during hypoxia in this preparation without increasing total glycolytic flux or tissue high-energy phosphate content.

These findings may shed some light on the controversy over whether the beneficial effects of elevated glucose are related to a direct effect on anaerobic glycolysis or to secondary metabolic and nonmetabolic sequelae. Although GIK increases glucose uptake during ischemia $(5,7,9,12)$, some investigators $(7,9)$ have argued that the increase in glycolytic flux is likely to be insufficient to account for the improvement in cardiac function. Although the metabolic effects of GIK appear to be highly dependent on the model of ischemia, the results of this study show that elevated glucose can have a direct metabolic effect on anaerobic glycolysis during hypoxia (i.e., enhance glucose utilization and prevent glycogenolysis) without increasing total glycolytic flux, and that this effect correlates with improved cardiac function.

To determine whether the beneficial effects of elevated glucose on cardiac function during hypoxia are related to its direct effects on anaerobic metabolism, it is important to exclude indirect effects of elevated glucose. Secondary metabolic and nonmetabolic mechanisms which could potentially contribute to the beneficial effects of GIK and its components during ischemia and hypoxia include the following: $(a)$ lowering of circulating levels of free fatty acids $(7,9,10)$, which are known to be deleterious in the setting of myocardial ischemia, (b) preservation of cardiac glycogen stores (28-31), (c) membrane-stabilizing effects of insulin $(7,27),(d)$ increased osmotic pressure (5), $(e)$ free radical-scavenging effects of glucose $(18,43)$, and $(f)$ facilitation of high-energy phosphate production by a nonglycolytic pathway. Although these mechanisms may be important in other experimental models, their contribution to the beneficial effects of glucose during hypoxia in the present study is probably not great. Fatty acid metabolism during hypoxia may be deleterious because of its oxygen-wasting effects and because it leads to accumulation toxic intermediates such as long chain acylcarnitines and acylcoenzyme A. However, recent work has shown that beneficial effects of inhibitors of fatty acid metabolism during ischemia may be related to their stimulation of glucose metabolism since they did not reduce accumulation of these toxic intermediates (44). We cannot absolutely exclude the possibility that $50 \mathrm{mM}$ glucose exerted its beneficial effects by influencing endogenous fatty acid metabolism during hypoxia. However, this seems unlikely since exogenous fatty acids were not provided as a metabolic substrate in our experiments, metabolism of endogenous triglycerides and fatty acids should have been markedly suppressed by the very low perfusate oxygen tension, and $50 \mathrm{mM}$ glucose did not improve cellular high-energy phosphate levels during hypoxia.
The hypothesis that a critical tissue level of glycogen during hypoxia is necessary to support cardiac function is also not supported by our results. Although $50 \mathrm{mM}$ glucose prevented net glycogenolysis during hypoxia, the beneficial effects of 50 $\mathrm{mM}$ glucose on cardiac function during hypoxia did not appear to depend on the tissue level of glycogen at the onset of hypoxia, since glycogen-depleted hearts tolerated hypoxia as well as non glycogen-depleted hearts in the presence of $50 \mathrm{mM}$ glucose. Conversely, the tissue glycogen level at the onset of hypoxia was important to hearts exposed to $5 \mathrm{mM}$ glucose during hypoxia. In this setting glycogen-depleted hearts tended to do worse than non-glycogen-depleted hearts, reflecting their dependence on endogenous glycogen to maintain total glycolytic flux. The latter result also indicates our method of glycogen depletion was effective. Although we did not quantitate the extent of glycogen depletion in the "glycogen-depleted" hearts, under similar conditions others have shown a $>50 \%$ reduction in tissue glycogen (31), consistent with the $\sim 50 \%$ reduction in developed tension we observed in our "glycogendepleted" preparations.

Membrane-stabilizing effects of insulin could not explain the benefit of increased glucose concentration during hypoxia in our study since all of the hypoxic solutions contained the same concentration of insulin and there was still a benefit seen with $50 \mathrm{mM}$ glucose. With $5 \mathrm{mM}$ glucose present, removal of insulin was detrimental during hypoxia, but was also associated with a lower total glycolytic flux. In this case we could not determine whether the lack of insulin contributed to hypoxic cardiac dysfunction independently of its effect on total glycolytic flux.

In a few studies it has been suggested that the benefits of elevated glucose were due to an osmotic effect, since nonmetabolizable sugars were equally effective (5) and increased osmolarity is known to reduce ischemic dysfunction $(45,46)$. Our findings are consistent with the majority of studies which have concluded that a benefit of GIK cannot be attributed exclusively to an osmotic effect $(7,11,12,16)$, since osmolarity was balanced with sucrose in all of the solutions we used.

Glucose and other sugars are known to act as free radical scavengers, and could potentially reduce hypoxic injury by this mechanism $(18,43)$. However, since the glucose + sucrose concentration was the same $(50 \mathrm{mM})$ in all of our experimental solutions, their effectiveness at scavenging free radicals should have been approximately equivalent during hypoxia and identical during reoxygenation, since all preparations were reoxygenated with $5 \mathrm{mM}$ glucose $/ 45 \mathrm{mM}$ sucrose perfusate.

Finally, it is possible that supraphysiologic glucose concentrations facilitated high-energy phosphate production by a nonglycolytic metabolic pathway during hypoxia. For example, it has been shown that glutamic acid improves cardiac function during ischemia by facilitating anaerobic GTP or ATP production via conversion of $\alpha$-ketoglutarate to succinate (47) or by improving the cytosolic NAD/NADH ratio (48). We did not measure either glycolytic or tricarboxylic acid cycle intermediates during hypoxia to evaluate this possibility, but consider it unlikely since no exogenous amino acids were provided as substrates in our experiments, and tissue high energy phosphate content after $50 \mathrm{~min}$ of hypoxia was not increased by $50 \mathrm{mM}$ glucose.

Effects of elevated glucose on $K^{+}$efflux during hypoxia. Despite its beneficial effects on contractile performance and 
action potential duration, $50 \mathrm{mM}$ glucose did not prevent the increase in ${ }^{42} \mathrm{~K}^{+}$efflux during hypoxia. The mechanism of increased $\mathrm{K}^{+}$efflux during hypoxia is not resolved, but may be due to an increase in membrane $\mathrm{K}^{+}$conductance via activation of ATP-sensitive $\mathrm{K}^{+}$channels (49) or due to $\mathrm{K}^{+}$efflux coupled to lactate and phosphate efflux (50). Others (51) have shown that in contrast to $5 \mathrm{mM}$ glucose, $50 \mathrm{mM}$ glucose prevented both the increase in outward $\mathrm{K}^{+}$current and action potential duration shortening during hypoxia in voltageclamped papillary muscles (presumed due mainly to activation of the ATP-sensitive $\mathrm{K}^{+}$current). Our finding that $50 \mathrm{mM}$ glucose prevented action potential duration shortening during hypoxia but did not prevent the increase in $\mathrm{K}^{+}$efflux may suggest that during hypoxia with glucose present anion-coupled $\mathrm{K}^{+}$efflux is an important cause of increased cellular $\mathrm{K}^{+}$ efflux. This is consistent with our recent observation that glyburide, a blocker of ATP-sensitive $\mathrm{K}^{+}$channels which completely prevented the increase in ${ }^{42} \mathrm{~K}^{+}$efflux during hypoxia without glucose present (52), only partially blocked the increase in ${ }^{42} \mathrm{~K}^{+}$efflux during hypoxia with $5 \mathrm{mM}$ glucose present (Weiss and Lamp, unpublished observations). Also, quantitatively the net efflux of lactate and inorganic phosphate during hypoxia exceeds the efflux of $\mathrm{K}^{+}$manyfold on a moleto-mole basis (53). If increased $\mathrm{K}^{+}$efflux is predominantly anion coupled during hypoxia with glucose present, one would not expect $50 \mathrm{mM}$ glucose to have decreased ${ }^{42} \mathrm{~K}^{+}$efflux during hypoxia since it did not reduce lactate efflux or high energy phosphate breakdown.

Possible mechanisms underlying the superiority of exogenous glucose utilization at preserving cardiac function during hypoxia. Determining the precise mechanism by which enhanced utilization of exogenous glucose improved cardiac function during hypoxia without increasing total glycolytic flux or tissue high-energy phosphate levels was beyond the scope of this study. However, assuming that the potential secondary effects of elevated glucose discussed above were not important, several possibilities are worth considering. First, cellular factors which control the proportions of total glycolytic flux derived from exogenous glucose vs. glycogen during hypoxia may also play a key role in modulating the susceptibility of the heart to electromechanical dysfunction. For example release of endogenous catecholamines during hypoxia may have been suppressed by supraphysiologic glucose concentrations. Cyclic AMP is known to have deleterious effects on cardiac function during myocardial ischemia $(54,55)$ and is also fundamentally involved in the activation of glycogenolysis. Since $50 \mathrm{mM}$ glucose suppressed net glycogenolysis during hypoxia, it is reasonable to suppose that this effect was mediated by reduced levels of cyclic AMP. Carlsson (56) found that noradrenaline release during low flow ischemia was greater in hearts which were glycogen-depleted or exposed to glucose-free perfusate or to iodoacetate to inhibit glycolysis, although he did not compare physiologic and supraphysiologic glucose concentrations. Although we did not find any difference in tissue cyclic AMP levels after $50 \mathrm{~min}$ of hypoxia in hearts exposed to physiologic or $50 \mathrm{mM}$ glucose, it is possible that significant differences were present at earlier times. This is a relevant possibility since most of the benefit of $50 \mathrm{mM}$ glucose appeared to occur during the first $25 \mathrm{~min}$ of hypoxia (Fig. 9). Thus reduction of catecholamine release and tissue cyclic AMP levels by $50 \mathrm{mM}$ glucose during hypoxia would provide an attractive explanation for our results. This mechanism would also be consistent with a previous study demonstrating that catecholamine depletion with reserpine increased tissue glycogen stores in exerting a protective effect against hypoxic cardiac dysfunction (29). Thus one could speculate that the cardioprotective effect of elevated glucose may be functionally similar to beta adrenergic blockade.

A second possibility is that exogenous glucose utilization may be intrinsically superior to glycogenolysis at supporting cardiac function during hypoxia. It is conceivable that the breakdown of glycogen in itself could be detrimental to the heart due to accumulation of an unidentified metabolic byproduct. However there are only a few metabolic steps that are not shared by exogenous glucose metabolism and glycogenolysis, which makes this explanation unlikely. Glycogen breakdown is also associated with an intrinsically greater net ATP production per molecule of lactate generated than is metabolism of exogenous glucose. Another possibility is that glycolytic pathways may be compartmentalized in heart. According to this hypothesis, high-energy phosphates generated from exogenous glucose but not glycogenolysis might be preferentially utilized to support key cellular functions which determine the severity of cardiac dysfunction during hypoxia and after reoxygenation. There is considerable evidence that glycolysis is a preferential source of high-energy phosphates supporting membrane function and preventing irreversible damage during ischemia and metabolic inhibition in heart $(35,57-65)$, and in vascular smooth muscle it has been shown that highenergy phosphates derived from exogenous glucose are utilized differently than high-energy phosphates derived from glycogenolysis (66). The basis for this compartmentalization may be related to localization of key glycolytic enzymes at specific sites in the cell $(64,65)$ that maintain adenine nucleotides locally at concentrations not necessarily reflected by total tissue levels of high-energy phosphates. It is possible that if phosphorylase and phosphoglucomutase, the enzymes necessary to convert glycogen to glucose-6-phosphate, were not present along with the other key glycolytic enzymes at these sites, then glycogen might not be able to substitute effectively for exogenous glucose as a metabolic substrate. Alternatively, it is possible that the progressive depletion of glycogen during hypoxia with a physiologic glucose concentration present may reduce high energy phosphate supply to a structure preferentially dependent on glycogenolysis. Glycogenolytic enzyme complexes have been shown to be specifically associated with the sarcoplasmic reticulum in heart (67), and prevention of contracture during hypoxia has been reported to be preferentially dependent on glycolysis (68). These findings may be relevant to our observation that rest tension was parameter of cardiac function most significantly benefited by $50 \mathrm{mM}$ glucose during hypoxia (Fig. 2). However, this hypothesis remains highly speculative at the present time, and our results do not any provide direct proof for such a mechanism.

A final possibility is that beneficial effects of elevated glucose are due to effects on the nonmyocyte components of the heart. For example, it is conceivable that elevated glucose might modulate the susceptibility of myocytes to hypoxic injury primarily by preventing vasculature dysfunction. In this case the metabolic differences we observed may be irrelevant to the cardioprotective effect of elevated glucose. Although we have no direct evidence for or against this possibility, in this 
preparation coronary flow was maintained at a constant level throughout which would ensure homogeneous perfusion unless major changes in vasculature shunting occurred with elevated glucose. Another point worth remembering is that the metabolic measurements in this study represent the combined metabolic activity of both the myocyte and nonmyocyte components of the heart, whereas the functional measurements reflect the myocyte population only. We cannot exclude the possibility that offsetting effects of elevated glucose on glycolytic flux in the myocyte and nonmyocyte components obscured a direct relationship between total glycolytic flux and hypoxic function in the myocyte population. This seems unlikely, however, since glucose would be expected to qualitatively have the same effects on glycolysis in both cellular components, and the effects on tissue glycogen (predominantly located in the myocyte component) appropriately parallelled the effects on exogenous glucose utilization.

Limitations and potential relevance of the study to myocardial ischemia. In light of the increasingly interventional approaches being used in the treatment of ischemic heart disease syndromes, defining mechanisms by which cardioprotective strategies can be improved has become increasingly important. In attempting to relate the results of this study to more clinically relevant models of myocardial injury, however, a number of important limitations must be recognized. The rabbit septal preparation is an intrinsically low work preparation and, under normoxic conditions at physiologic coronary perfusion rates used in this study, aerobically metabolizes lactate derived from exogenous glucose to a lesser extent than more physiologic heart preparations (39). This low rate of lactate metabolism, however, is not due to inadequate oxygen delivery since increasing flow rate has minor effects on lactate production and tension development despite several-fold increases in oxygen delivery (39). Also during control aerobic perfusion, the preparation remains stable both functionally and metabolically for a number of hours $(39,69-71)$, although tissue glycogen levels fall gradually over time (39), as we have confirmed. Nevertheless we cannot exclude the possibility that the mechanisms underlying the benefits of elevated glucose during hypoxia in this preparation may not be operative in more physiologic models. More generally, observations in hypoxic muscle cannot necessarily be extrapolated to ischemia, the more clinically relevant situation. We also studied a very high concentration $(50 \mathrm{mM})$ of glucose in order to maximize its metabolic effects and have not examined whether glucose concentrations in a more clinically attainable range (10-20 mM) have equivalent beneficial effects. Nevertheless, the finding that elevated glucose may benefit hypoxic myocardium by a direct metabolic effect without increasing total glycolytic flux raises the possibility that a similar effect may contribute to the beneficial effects of GIK therapy during myocardial ischemia.

\section{References}

1. Runnman, E. M., and J. N. Weiss. 1988. Exogenous glucose is superior to glycogenolysis at preserving cardiac function during hypoxia. Circulation. 78(Suppl. II):II-261. (Abstr.)

2. Goulston, A. 1911. A note on beneficial effect of the ingestion of cane sugar in certain forms of heart disease. Br. Med. J. 1(Pt. 1):615.

3. Sodi-Pallares, D, M. R. Testelli, B. L. Fishleder, A. Bisteni, G. A. Medrano, C. Friedland, and A. DeMicheli. 1962. Effects of an intrave- nous infusion of a potassium-glucose-insulin solution on the electrocardiographic signs of myocardial infarction: a preliminary clinical report. Am. J. Cardiol. 9:166-181.

4. Sodi-Pallares, D., A. Bisteni, G. A. Medrano, M. R. Testelli, and A. D. De Micheli. 1963. Polarizing treatment of acute myocardial infarction: possibility of its use in other cardiovascular conditions. Dis. Chest. 43:424-432.

5. Burke, W. M., S. K. Asokan, C. B. Moschos, H. A. Oldewurtel, and T. J. Regan. 1969. Effects of glucose and nonglucose infusion on myocardial potassium ion transfers and arrhythmias during ischemia. Am. J. Cardiol. 24:713-722.

6. Maroko, P. R., P. Libby, B. E. Sobel, C. M. Bloor, H. D. Sybers, W. E. Shell, J. W. Covell, and E. Braunwald. 1972. Effect of glucoseinsulin-potassium on myocardial infarction following experimental coronary artery occlusion. Circulation. 45:1160-1175.

7. Opie, L. H. 1975. Metabolism of free fatty acids, glucose, and catacholamines in acute myocardial infarction. Am. J. Cardiol. 36:938-952.

8. Opie, L. H., K. Bruyneel, and P. Owens. 1975. Effects of glucose, insulin, and potassium infusion on the tissue metabolic changes within the first hour of myocardial infarction in the baboon. Circulation. 52:49-57.

9. Opie, L. H., and P. Owen. 1976. Effect of glucose-insulin-potassium infusions on arteriovenous differences of glucose and of free fatty acids, and on tissue metabolic changes in dogs with developing myocardial infarction. Am. J. Cardiol. 38:310-321.

10. Liedtke, A. J., H. C. Hughes, and J. R. Neely. 1976. Effects of excess glucose and insulin on glycolytic metabolism during experimental myocardial ischemia. Am. J. Cardiol. 38:17-27.

11. Ahmed, S., C. H. Lee, H. A. Odlewurtel, and T. J. Regan. 1978. Sustained effect of glucose-insulin-potassium on myocardial performance during regional ischemia. J. Clin. Invest. 61:1123-1135.

12. Apstein, C. S., F. N. Gravino, and C. C. Haudenchild. 1983. Determinants of a protective effect of glucose and insulin on the ischemic myocardium. Circ. Res. 52:515-526.

13. MacLeod, D. P., and K. Prasad. 1969. Influence of glucose on transmembrane action potential of papillary muscle. J. Gen. Physiol. 53:792-814.

14. McDonald, T. F., and D. P. MacLeod. 1971. Maintenance of resting potential in anoxic guinea pig ventricular muscle: electrogenic sodium pumping. Science (Wash. DC). 172:570-572.

15. Hearse, D. J., and E. B. Chain. 1972. The role of glucose in the survival and recovery of anoxic isolated perfused rat heart. Biochem. $J$. 128:1125-1133.

16. McDonald, T. F., and D. P. MacLeod. 1973. Metabolism and the electrical activity of anoxic ventricular muscle. J. Physiol. (Lond.). 229:560-582.

17. Henry, P. O., B. E. Sobel, and E. Braunwald. 1974. Protection of hypoxic guinea pig heart with glucose and insulin. Am. J. Physiol. 226:309-313.

18. Hess, M. L., E. Okabe, J. Poland, M. Warner, J. R. Stewart, and L. J. Greenfield. 1983. Glucose, insulin, potassium protection during the course of hypothermic global ischemia and reperfusion: a new proposed mechanism by scavenging of free radicals. J. Cardiovasc. Pharmacol. 5:35-43.

19. Surawicz, B. 1968. Evaluation of treatment of acute myocardial infarction with potassium, glucose and insulin. Prog. Cardiol. 10:545559.

20. Lesch, M., L. E. Teichholz, J. S. Soeldner, and R. Gorlin. 1974. Ineffectiveness of glucose, potassium and insulin infusion during pacing stress in chronic ischemic heart disease. Circulation. 44:10281037.

21. Rogers, W. J., A. W. Stanley, Jr., J. B. Breining, J. W. Prather, H. G. McDaniel, R. E. Moraski, J. A. Mantle, R. O. Russell, Jr., and C. E. Rackley. 1976. Reduction of hospital mortality rate of acute myocardial infarction with glucose-insulin-potassium infusion. $\mathrm{Am}$. Heart J. 92:441-454. 
22. Chiong, M., R. West, and J. O. Parker. 1976. The protective effect of glucose-insulin-potassium on the response to atrial pacing. Circulation. 54:37-46.

23. Thadani, U., M. A. Chiong, and J. O. Parker. 1980. Effects of low and high glucose in a glucose-insulin-potassium infusion in hemodynamics and exercise tolerance in patients with angina pectoris. $\mathrm{Cir}$ culation. 61:266-276.

24. Rackley, C. E., R. O. Russell, W. J. Rogers, and S. E. Papapierto. 1981. Clinical experience with glucose-insulin-potassium therapy in acute myocardial infarction. Am. Heart J. 102:1038-1049.

25. Whitlow, P. L., W. J. Rogers, L. R. Smith, H. G. MacDaniel, S. E. Papapierto, J. A. Mantle, J. R. Logic, R. O. Russell, and C. E. Rackley. 1982. Enhancement of left ventricular function by glucoseinsulin-potassium infusion in acute myocardial infarction. Am. J. Cardiol. 49:811-820.

26. Martinez, E. E., J. S. Telles, T. L. R. Martinez, O. P. Portugal, R. F. Guimaraes, J. L. V. Herrmann, E. N. Lamounier, A. A. De Paola, C. R. C. Auriemo, and J. A. Ambrose. 1987. The effects of glucose on myocardial substrate utilization in acute myocardial infarction or angina pectoris. Am. J. Cardiol. 60:947-951.

27. Muller, J. E., S. Mochizuki, J. K. Koster, J. J. Collins, L. H. Cohn, and J. R. Neely. 1978. Insulin therapy for depressed myocardial contractility after prolonged ischemia. Am. J. Cardiol. 41:1215-1121.

28. Gelli, M. G., G. Enhorning, E. Hultman, and J. Bergstrom. 1968. Glucose infusion in the pregnant rabbit and its effect on glycogen content and activity of the foetal heart under anoxia. Acta Paediatr. Scand. 57:209-215.

29. Scheuer, J., and S. W. Stezoski. 1970. Protective role of increased myocardial glycogen stores in cardiac anoxia in the rat. Circ. Res. 27:835-849.

30. Reimer, K. A., M. M. Rasmussen, and R. B. Jennings. 1973. Reduction by propranolol of myocardial necrosis following temporary coronary artery occlusion in dogs. Circ. Res. 33:353-363.

31. Lagerstrom, C. F., W. E. Walker, and H. Taegtmeyer. 1988. Failure of glycogen depletion to improve left ventricular function of the rabbit heart after hypothermic ischemic arrest. Circ. Res. 63:81-88.

32. Weiss, J. N., and K. I. Shine. 1982. [K+] $]_{0}$ accumulation and electrophysiological alterations during early myocardial ischemia. Am. J. Physiol. 243:H318-H327.

33. Woodbury, J. W., and A. J. Brady. 1956. Intracellular recording from moving tissue with a flexibly mounted ultramicroelectrode. Science (Wash. DC). 123:100-101.

34. Guttman, I., and A. W. Wahlefeld. 1974. Lactate determination with lactate dehydrogenase and NAD. In Methods of Enzymatic Analysis. H. Bergmeyer, editor. Academic Press, Inc., New York. 1464-1468.

35. Weiss, J. N., and B. Hiltbrand. 1985. Functional compartmentalization of glycolytic versus oxidative metabolism in isolated rabbit heart. J. Clin. Invest. 75:436-447.

36. Dubiak, G. R., and A. Scarpa. 1983. ${ }^{31}$ P NMR studies of single muscle cells isolated from Barnacle depressor muscle. Biochemistry. 22:3531-3536.

37. Humphrey, S. M., D. G. Holliss, and R. N. Seelye. 1985. Myocardial adenine pool depletion and recovery of mechanical function following ischemia. Am. J. Physiol. 248:H644-H651.

38. Van Handel, E. 1964. Estimation of glycogen in small amounts of tissue. Anal. Biochem. 11:256-265.

39. Marshall, R. C., W. W. Nash, K. I. Shine, M. E. Phelps, and N. Richiutti. 1981. Glucose metabolism during ischemia due to excessive oxygen demand or altered coronary flow in the isolated rabbit septum. Circ. Res. 49:640-648.

40. Morgan, H. E., J. R. Neely, and Y. Kira. 1984. Factors determining the utilization of glucose in isolated rat hearts. Basic Res. Cardiol. 79:292-299.

41. Magnusson, I., V. Chandramouli, W. C. Schumann, K. Kumaran, J. Wahren, and B. R. Landau. 1987. Quantitation of the path- ways of hepatic glycogen formation on ingesting a glucose load. J. Clin. Invest. 80:1748-1754.

42. Goldhaber, J. I., S. Ji, S. T. Lamp and J. N. Weiss. 1989. Effects of exogenous free radicals on electromechanical function and metabolism in isolated rabbit and guinea pig ventricle. Implications for ischemia and reperfusion injury. J. Clin. Invest. 83:1800-1809.

43. Hess, M. L., and N. H. Manson. 1984. Molecular oxygen: friend and foe. The role of the oxygen free radical system in the calcium paradox, the oxygen paradox and ischemia/reperfusion injury. $J$. Mol. Cell. Cardiol. 16:969-985.

44. Lopaschuk, G. D., S. R. Wall, P. M. Olley, and N. J. Davies. 1988. Etomoxir, a carnitine palmitoyltransferase I inhibitor, protects hearts from fatty acid-induced ischemic injury independent of changes in long chain acylcarnitine. Circ. Res. 63:1036-1043.

45. Willerson, J. T., W. J. Powell, T. E. Gulney, J. J. Stark, C. S. Sanders, and A. Leaf. 1973. Improvement in myocardial function and coronary blood flow in ischemic myocardium after mannitol. J. Clin. Invest. 51:2989-2998.

46. Leaf, A. 1973. Cell swelling: a factor in ischemic tissue injury. Circulation. 48:455-458.

47. Bittl, J. A., and K. I. Shine. 1983. Protection of ischemic rabbit myocardium by glutamic acid. Am. J. Physiol. 245:H406-H412.

48. Wright, G. 1985. Amino acids in the treatment of ischemic heart disease. J. Mol. Cell. Cardiol. 17:441-443.

49. Noma, A. 1983. ATP-regulated $\mathrm{K}^{+}$channels in cardiac muscle. Nature (Lond.). 305:147-148.

50. Kleber, A. G. 1984. Extracellular potassium accumulation in acute myocardial ischemia. J. Mol. Cell. Cardiol. 16:389-394.

51. Conrad, C. H., R. G. Mark, and O. L. Bing. 1983. Outward current and repolarization in hypoxic rat myocardium. Am. J. Physiol. 244:H341-H350.

52. Venkatesh, N., S. T. Lamp, and J. N. Weiss. 1989. Effects of sulfonylureas on $\mathrm{K}^{+}$loss during myocardial ischemia and metabolic inhibition. Circulation. 80(Suppl. II):II-607. (Abstr.).

53. J. N. Weiss, S. T. Lamp, and K. I. Shine. 1989. $\mathrm{K}^{+}$loss during myocardial hypoxia and ischemia: relationship to anion efflux in isolated rabbit ventricle. Am. J. Physiol. 256:H1165-H1175.

54. Podzuweit, T., A. G. Dalby, G. W. Cherry, and L. H. Opie. 1978. Cyclic AMP levels in ischemic and non-ischemic myocardium following coronary artery ligation: relation to ventricular fibrillation. $J$. Mol. Cell. Cardiol. 10:81-94.

55. Lubbe, W. F., O. L. Bricknell, T. Podzuweit, and L. H. Opie. 1976. Cyclic adenosine monophosphate as a determinant of vulnerability to ventricular fibrillation in the isolated rat heart. Cardiovasc. Res. 10:697-702.

56. Carlsson, L. 1988. A crucial role of ongoing anaerobic glycolysis in attenuating acute ischemia-induced release of myocardial noradrenaline. J. Mol. Cell. Cardiol. 20:247-253.

57. Bricknell, O. L., and L. H. Opie. 1978. Effects of substrates and tissue metabolic changes in the isolated rat heart during underperfusion and on the release of lactate dehydrogenase and arrhythmias during reperfusion. Circ. Res. 43:102-115.

58. Opie, L. H., and O. L. Bricknell. 1979. Role of glycolytic flux in effect of glucose in decreasing fatty-acid-induced release of lactate dehydrogenase from isolated coronary ligated rat heart. Cardiovasc. Res. 13:693-702.

59. Higgins, T. J., D. Allsopp, P. J. Bailey, and E. D. D’Souza. 1981. The relationship between glycolysis, fatty acid metabolism, and membrane integrity in neonatal myocytes. J. Mol. Cell. Cardiol. 13:599-615.

60. Higgins, T. J., P. J. Bailey, and D. Allsopp. 1982. Interrelationship between cellular metabolic status and susceptibility of heart cells to attack by phospholipase. J. Mol. Cell. Cardiol. 14:645-654.

61. Higgins, T. J., and P. J. Bailey. 1983. The effects of cyanide and iodoacetate intoxication and ischemia on enzyme release from the perfused rat heart. Biochem. Biophys. Acta. 762:67-75.

62. Hasin, Y., and W. H. Barry. 1984. Myocardial metabolic inhi- 
bition and membrane potential, contraction, and potassium uptake. Am. J. Physiol. 247:H322-329.

63. Hasin, Y., A. Doorey, and W. H. Barry. 1984. Electrophysiologic and mechanical effects of metabolic inhibition of high energy phosphate production in cultured chick embryo ventricular cells. $J$. Mol. Cell. Cardiol. 16:1009-1021.

64. Weiss, J. N., and S. T. Lamp. 1987. Glycolysis preferentially inhibits ATP-sensitive $\mathrm{K}^{+}$channels in isolated guinea pig ventricular myocytes. Science (Wash. DC). 238:67-69.

65. Weiss, J. N., and S. T. Lamp. 1989. Cardiac ATP-sensitive $\mathrm{K}^{+}$ channels: evidence for preferential regulation by glycolysis. J. Gen. Physiol. 94:911-935.

66. Lynch, R. M., and R. J. Paul. 1983. Compartmentation of glycolytic and glycogenolytic metabolism in vascular smooth muscle. Science (Wash. DC). 222:1344-1346.

67. Entman, M. L., K. Kanike, M. A. Goldstein, T. E. Nelson, E. P.
Bornet, T. W. Futch, and A. Schwartz. 1976. Association of glycogenolysis with cardiac sarcoplasmic reticulum. J. Biol. Chem. 251:31403146.

68. Anderson, G. L., and R. G. Morris. 1978. Role of glycolysis in the relaxation process in mammalian cardiac muscle: comparison of the influence of glucose and 2-deoxyglucose on maintenance of resting tension. Life Sci. 23:23-32.

69. Shelburne, J. C., S. D. Serena, and G. A. Langer. 1967. Ratetension staircase in rabbit ventricular muscle: relation to ionic exchange. Am. J. Physiol. 213:1115-1124.

70. Poole-Wislon, P. A., and G. A. Langer. 1975. Effect of pH on ionic exchange and function in rat and rabbit myocardium. Am. J. Physiol. 229:570-581.

71. Rau, E. E., and G. A. Langer. 1978. Dissociation of energetic state and potassium loss from anoxic myocardium. Am. J. Physiol. 235:H537-H543. 